\title{
Review
}

Technology/Device

Diabetes Metab J 2020;44:819-827

https://doi.org/10.4093/dmj.2020.0088

pISSN 2233-6079 · eISSN 2233-6087

DIABET\&S \& METABOLISM JOURNAL

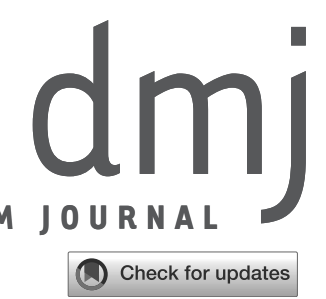

\section{Present and Future of Digital Health in Diabetes and Metabolic Disease}

\author{
Sang Youl Rhee ${ }^{1,2}$, Chiweon Kim³ ${ }^{3}$, Dong Wook Shin ${ }^{4,5}$, Steven R. Steinhubl ${ }^{2}$ \\ ${ }^{1}$ Department of Endocrinology and Metabolism, Kyung Hee University School of Medicine, Seoul, Korea, \\ ${ }^{2}$ Department of Digital Health, Scripps Research Translational Institute, La Jolla, CA, USA, \\ ${ }^{3}$ Department of Internal Medicine, Seoul Wise Hospital, Uiwang, \\ ${ }^{4}$ Department of Family Medicine/Supportive Care Center, Samsung Medical Center, Sungkyunkwan University School of Medicine, Seoul, \\ ${ }^{5}$ Department of Digital Health, Samsung Advanced Institute for Health Sciences \& Technology, Sungkyunkwan University, Seoul, Korea
}

The use of information and communication technology (ICT) in medical and healthcare services goes beyond everyday life. Expectations of a new medical environment, not previously experienced by ICT, exist in the near future. In particular, chronic metabolic diseases such as diabetes and obesity, have a high prevalence and high social and economic burden. In addition, the continuous evaluation and monitoring of daily life is important for effective treatment and management. Therefore, the wide use of ICTbased digital health systems is required for the treatment and management of these diseases. In this article, we compiled a variety of digital health technologies introduced to date in the field of diabetes and metabolic diseases.

Keywords: Diabetes mellitus; Education; Mobile applications; Nutritional sciences; Obesity; Prediabetic state; Prevention and control; Self care; Smartphone; Wearable electronic devices

\section{INTRODUCTION}

With the development of information and communication technology (ICT), radical changes have occurred in the daily lives of modern people. Such change began with the growth of personal computers, and rapidly increased with the expansion of wired internet. However, even more dramatic changes have more recently occurred with the growth of smartphones and wireless technology.

Today, major components of ICT are not only used in everyday life, but also in medical and healthcare services. In the near future, the new medical environment will see changes not previously experienced.

Metabolic diseases such as diabetes mellitus (DM) and obesity are chronic diseases with a high prevalence and high so- cial, economic burdens [1,2]. In addition, the constant evaluation and management of daily life habits, such as diet, exercise, and medication prescribed by a doctor, are important. Therefore, the wide use of various digital health components in this chronic disease area is expected, and will likely shift the current medical paradigm radically.

This article intends, firstly, to summarize the use of various digital health technologies developed thus far in the area of $\mathrm{DM}$ and metabolic diseases and, secondly, to predict the future evolution of this field.

\section{DIGITAL HEALTH}

Digital health is a methodology that uses ICT to more efficiently personalize, and precisely address, the various prob-
Corresponding authors: Sang Youl Rhee (D) https://orcid.org/0000-0003-0119-5818 Department of Endocrinology and Metabolism, Kyung Hee University School of

Medicine, 23 Kyungheedae-ro, Dongdaemun-gu, Seoul 02447, Korea

E-mail: rheesy@khu.ac.kr
This is an Open Access article distributed under the terms of the Creative Commons Attribution Non-Commercial License (https://creativecommons.org/licenses/by-nc/4.0/) which permits unrestricted non-commercial use, distribution, and reproduction in any medium, provided the original work is properly cited.

Steven R. Steinhubl (D) https://orcid.org/0000-0002-9256-7914

Department of Digital Health, Scripps Research Translational Institute, 3344 North

Torrey Pines Court, La Jolla, CA 92037, USA

E-mail: steinhub@scripps.edu 
lems people face with health $[3,4]$. In addition to healthcare, experts and stakeholders from various fields such as engineering, public health, and the economy are also involved in the digital health arena.

In general, the provision of digital health services facilitates the collection of data related to an individual's condition, analyzes data to evaluate clinical or pre-clinical conditions, and provides the personalized intervention or monitoring for an area of interest $[3,5]$. These services not only include traditional interfaces such as e-mail, text messages, and web, but also new technology-based services such as smartphones, applications, and wearable devices (Fig. 1) [6]. Furthermore, the digital health field incorporates advanced and specialized services directly utilized by doctors and healthcare professionals.

\section{DM, METABOLIC DISEASES, AND DIGITAL HEALTH}

Due to the nature of metabolic diseases such as DM and obesity, several attempts have been made to apply elements of digital health for effective treatment and management $[7,8]$. First, chronic metabolic diseases have a high prevalence and high social and economic costs [1,9]. Second, most are difficult to treat and manage only with medical services in hospitals, and continuous management and monitoring of daily lifestyle is necessary. In particular, it is possible to utilize digital health components for health promotion and disease prevention from pre-clinical phases such as obesity and pre-diabetes [10]. This provides various information suitable for the user's clinical condition, improves self-management efficiency, improves the clinical course through personalized intervention, and can be used for early screening and effective treatment of complications.

\section{DIGITAL HEALTH IN PRE-CLINICAL CONDITION}

In pre-clinical situations where clinical symptoms are not prominent, the following digital health elements can be utilized.

\section{Assessment of daily activity}

Wristbands, belts, patch-type wearable devices, and smartphone sensors can be used to measure and evaluate an individual's activity (Table 1). Indicators such as activity amount, activity intensity, and calorie consumption are automatically estimated and transmitted to the user while using these devices. Previous studies show the high accuracy of these measurement device indicators $[11,12]$. Improvements in recently released equipment now enable the monitoring of cardiovascular dis-
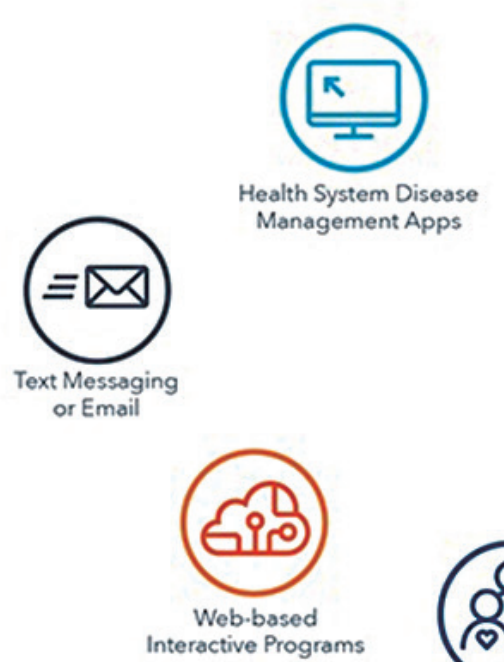
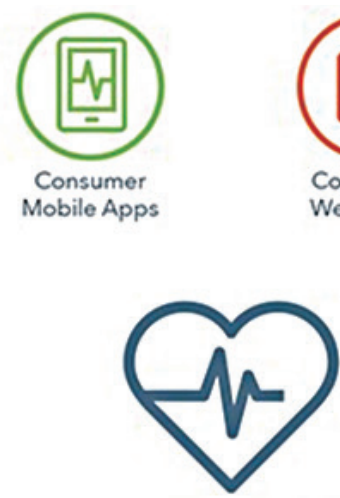

Digital Health
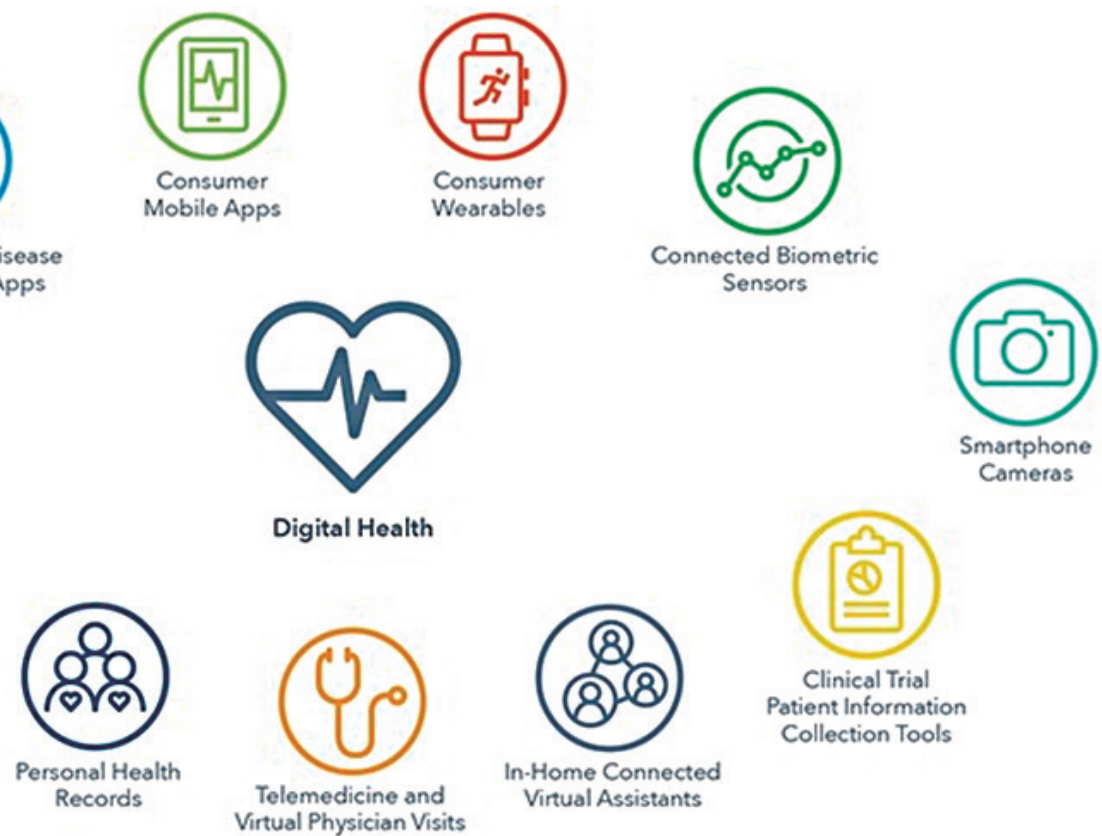

Virtual Physician Visits

Fig. 1. Various tools for digital health. Adapted from IQVIA by the policies for data download and sharing [6]. 
Table 1. Representative digital health-related factors that can be used in diabetes and metabolic diseases

\begin{tabular}{ll}
\hline Classification & \multicolumn{1}{c}{ Example } \\
\hline $\begin{array}{l}\text { Pre-clinical condition } \\
\text { Assessment of daily activity }\end{array}$ & $\begin{array}{c}\text { Activity tracker, heart rate, electrocardiogram, sleep quality } \\
\text { Evaluation of meal time, frequency, total food intake, and calorie pursuing automation } \\
\text { with the "food lens" function }\end{array}$ \\
$\begin{array}{ll}\text { Weight reduction/diabetes prevention } \\
\text { Obesity management applications, online diabetes prevention program interventions }\end{array}$ \\
$\begin{array}{l}\text { Patient education } \\
\begin{array}{l}\text { Advanced blood glucose measurement } \\
\text { Improvement of medication adherence }\end{array}\end{array}$ & $\begin{array}{l}\text { Evidence-based reference materials, Chatbot service } \\
\text { Cvaluation and management of complications }\end{array}$ \\
$\begin{array}{l}\text { Oral medication with biosensor, insulin dose calculator, digital insulin pen } \\
\text { Screening of retinopathy, and foot ulcer, detection and/or prediction of fall, hypertension } \\
\text { management, home urinalysis }\end{array}$ \\
$\begin{array}{l}\text { Direct involvement from healthcare professionals } \\
\text { Remote clinical trial }\end{array}$ & $\begin{array}{l}\text { Remote blood glucose monitoring, human coaching } \\
\text { 'ResearchKit', mSToPs study }\end{array}$ \\
\hline
\end{tabular}

ease-related indicators, such as heart rate and electrocardiogram (ECG), and lifestyle indicators, such as sleep quality $[13,14]$. Studies also report that these indicators can accurately reflect the clinical situation of chronic metabolic disease $[13,14]$. These monitoring systems need to be applied to prevention of cardiovascular disease in diabetes and metabolic diseases, and it is necessary to come up with measures that can be used more conveniently by users in the long term.

\section{Evaluation of eating habits}

The assessment of eating habits is important for the management of chronic metabolic diseases. However, to accurately assess an individual's diet over an extended period of time is very difficult. The quantitative evaluation of data is not easy due to variations in food selection, processing, cooking, and consumption methods for each race, culture, country, and individual. With the recent development of a continuous blood glucose meter and intestinal microbiome analysis, significant advances have been made in the methodology for individualized dietary assessment, at least in the field of diabetes and metabolic diseases.

The food diary, using a smartphone application, is a wellknown simple tool. However, it is difficult for a user to constantly record data based on his or her eating habits. The recent function of photographing a user's meal with a smartphone, and using these images to quantify the composition and calories of the food, has been developed [15,16]. Furthermore, it was recently confirmed that the blood glucose changes for a standardized diet show a significant difference according to the variety of individual intestinal microbiome [17,18]. A dietary recommendation service considering these individual characteristics was also released. Diet management is paramount in the management of diabetes and metabolic diseases. However, it is important to come up with more diverse and effective solutions to improve diet control, as it is also a very difficult part to keep track of diet habits and make behavioral changes.

\section{Weight reduction}

Beyond the simple recording or delivery of information, a number of interventional services to "promote health" have also been developed and distributed. Although these services have a medical purpose, they are implemented with the goal of disease prevention, and so differ from general medical practice. Some employers encourage digital health-based promotional activities for employees and provide incentives for users with high participation rates [19].

Intervention for weight loss is the most well-known service in this area. It is usually configured to record and manage various variables related to a user's daily life and provide feedback to successfully achieve a target weight. At least short-term effect has been demonstrated for some of these interventions $[8,20,21]$. However, variations in quality between services and insufficient scientific evidence of many services, highlights a need for user protection [22]. In addition, when a user who does not correspond to the recommended indication uses this kind of service, it may be possible to obtain a result that is dif- 
ferent from the expectation, but in general, caution is required because accurate guidance is insufficient. Weight loss is the result of a very complex factor affecting each other. More effective measures seem to be needed to monitor various factors, such as eating habits, exercise habits, stress, and sleep patterns, and to keep users following them.

\section{Prevention of DM}

In recent years, digital health technologies have been used to achieve more specialized medical goals, such as diabetes prevention. Diabetes prevention intervention using digital health was developed based on the core content of the well-known United States diabetes prevention program (DPP) [23]. In particular, in the United States, such online interventions for DPP are provided with a reimbursement for its cost [24,25].

The reimbursement of health insurance for the prevention of disease, not the treatment of disease, is currently rare. If this attempt proves to be successful, it will be an important milestone in the field of public health and digital health. Currently, research on the effectiveness of web-based intervention programs to prevent diabetes is being conducted in Korea, and the results will be announced soon [26].

\section{DIGITAL HEALTH FOR PEOPLE WITH DM}

Various digital health technologies have been introduced to improve the clinical course of people with diabetes. Such technologies provide reliable disease information, assist self-care management, and enable more effective interaction between patients, doctors, and healthcare professionals.

\section{Patient education}

Research shows that systematic education from an expert positively affects the clinical course of people with DM [27]. However, the implementation of effective diabetes education in the field is not easy. In Korea, for example, diabetes education from experts is not covered by medical insurance and is, therefore, particularly difficult.

Digital health technology enables people with DM to receive effective education at a low cost, regardless of time and location. Various digital health-based diabetes education programs, developed by experts, are actively spreading, some supported by studies proving their effectiveness [28]. Recently, advanced services using chat bots enable active user participation and question and answer sessions [29]. It needs to be accom- panied by a policy of providing effective training to patients and ensuring adequate benefits for both the medical staff and the patients.

\section{Advanced blood glucose measurement}

The portable blood glucose meter device was released long ago, but recently, blood sugar data can be automatically collected, stored, and analyzed with the connection of a smartphone and an application for effective self-management of people with DM.

Continuous blood glucose meters can be classified as a type of wearable device. The glucose of the interstitial fluid is measured at 5 minute intervals with a sensor inserted under the skin, which can be used for 3 to 7 days. Due to recent performance improvements, equipment without the need for calibration such as flash glucose monitoring system has been released, which makes checking blood sugar and obtaining real time readings possible, creating the possibility to proactively respond to hypoglycemia or hyperglycemia [30]. In particular, this device can usefully serve as a form of "artificial pancreas" for users, in conjunction with an insulin pump. Recently, the hybrid closed-loop artificial pancreas was approved by the U.S. food and drug administration (FDA) [31,32]. Also recently, a new bloodless glucose measurement technique, capable of real-time glucose reading, in the form of watches, tattoos, and contact lenses has been actively researched, and much progress is expected for monitoring blood glucose in people with DM in the future $[33,34]$.

\section{Improvement of medication adherence}

The majority of people with diabetes require lifelong oral or injectable medications. The use of a medication notification service, via a smartphone, can help improve their medication adherence [35]. Although not directly related to people with DM, recent attempts have been made to improve medication adherence for the treatment of schizophrenia by combining sensors with oral medications [36]. Possibly, therefore, this methodology will expand for the management of various other chronic diseases where adherence to drugs is important.

For insulin users, an insulin dose calculator has been developed to evaluate the amount of carbohydrates in a meal and provide an insulin dose based thereon [37]. In addition, for the convenience of insulin users, a digital insulin pen that supports automatic detection of insulin type, the fine adjustment of insulin dosage, and a notification function for injection time and hypoglycemia was released [38]. Increasing compliance with 
insulin use is very important, and it is also necessary to consider the application of IoT (Internet of Things) to monitor insulin use and the system that provides effective education.

\section{Evaluation and management of complications}

Digital health equipment for the evaluation and management of diabetes-specific chronic complications has also been developed and launched. For example, fundoscopy systems, using smartphones or handheld cameras, are expanding in scope to screen for diabetic retinopathy [39]. The collected images can be graded using machine learning, and effectively screened for persons in need of treatment by an ophthalmologist [40]. Diabetic foot ulcer screening equipment has also appeared [41], and is designed to scan the foot when the patient is on a weight scale. The image is then used to evaluate whether or not a foot ulcer is present. Furthermore, position detection sensors can identify a fall that may occur in an emergency situation such as a cardiovascular accident or hypoglycemia and, accordingly, equipment that can link with an emergency rescue service has been released [42].

\section{Direct involvement from healthcare professionals}

In the United States, a "virtual hospital" system is in operation. This system remotely collects clinical patient information, using various sensors and monitoring equipment in the patient's home, and performs remote clinical treatment and monitoring based on this data $[43,44]$. Furthermore, a pilot service to remotely monitor blood glucose information of people with DM, obtained through a continuous blood glucose meter, and provide personalized treatment information is also known [45]. In addition to blood sugar, a system has been developed to monitor various biological signals, and inform medical staff of important clinical changes in advance, even if the patient has no symptoms, by using an artificial intelligence monitoring algorithm. Obesity and diabetes management services that use online coaching directly related to medical professionals, rather than a simple algorithm, are also expanding [46,47].

\section{REMOTE CLINICAL TRIAL}

"ResearchKit" is a clinical research support service designed to conduct various essential clinical research tasks, such as consent, surveys, and data collection, with a smartphone [48]. This allows medical researchers to easily collect data and conduct effective clinical trials. In addition to DM, apps for clinical research on various diseases such as Parkinson's disease, autism, seizure, and sleep disorders are being developed and utilized [48-50].

The results of a large-scale remote clinical trial (mSToPs study) using a wearable ECG patch were recently introduced. In this study, major processes such as participant recruitment, informed consent, the delivery of wearable devices, data collection, and observation of clinical courses were performed remotely using a smartphone and electronic medical records [52]. Results showed that, the diagnostic rate of atrial fibrillation was significantly higher in users who used the ECG patch early [53]. Currently, follow-up studies on the effects of early atrial fibrillation detection on the long-term clinical course are underway. In addition, we are preparing relevant article by obtaining potentially meaningful results for the DM subgroup from this study.

\section{FUTURE PROSPECTS AND CHALLENGES THAT NEED TO BE RESOLVED}

Attempts are being made to introduce digital health elements into the current medical environment. However, it is difficult to embed digital health elements into general medical practice unless clinical efficacy and safety are verified, and a reasonable payment system is established [54].

The U.S. FDA operates a precertification program for some manufacturers to implement policies to increase innovation and access to digital health [55]. The program focuses on the digital health company, rather than on the product, so that precertified companies are expected to meet the same safety and effectiveness standard that the U.S. FDA expects [56]. The operation of these schemes can facilitate the entry of new digital health products into the market. However, current Korean regulations and laws make it difficult to spread digital health components. Moreover, since the Korean health insurance system operates as a single payer, price elasticity is low, and the provision of new treatment techniques tends to be conservative. There is a need to supplement and improve these systems.

More important than the discussion of insurance benefits is whether sufficient clinical evidence has been established for the relevant technology. Reliable research on new technologies related to digital health is not yet sufficient. In particular, verification is needed on how effective digital health-based services are compared to standard treatments in current clinical practice guidelines. In addition, verification is also needed on whether digital health is a treatment that can effectively utilize 
limited medical resources through cost-effectiveness studies.

In medicine, the results of randomized controlled trials (RCTs) or meta-analyses are considered as the highest evidence level. However, with the recent activation of digital health and big data-based research, new research results that are difficult to attempt in RCTs are appearing. Although such evidence does not satisfy the rigor of RCTs, meaningful results that can lead to changes in actual clinical behavior are presented arguably, in the future, such real world evidence should encourage the use of so-called "actionable data" that are sufficient for clinical or public health action that have been derived objectively and openly [57]. In Korea, a representative example of such "actionable data" is a population-based claims data, and many studies that are difficult to conduct RCTs are being conducted $[58,59]$. The accumulation of research results based on this philosophy is expected to greatly assist in the rapid spread of new medical technologies. In particular, in relation to the recent global public health crisis, such as COVID-19, this methodology is expected to contribute greatly in the future to promote the rapid introduction and diffusion of new digital health-related technologies such as telemedicine [60]. Although a variety of digital devices are being introduced, a healthcare system needs to be developed to ensure that devices tailored to the patient's characteristics are used and that data is accumulated over the long term, and that proper education and compensation are made to ensure that chronic diseases such as diabetes and metabolic diseases are ultimately better managed and complications are prevented.

\section{CONCLUSIONS}

"P4 medicine" is often mentioned as a key word for future medical care, and was created to mean that future health care is based on four key elements: disease prediction, prevention, personalization and patient participation [61]. However, in the meantime, many digital health-related technologies, already developed, can provide practical assistance to high-risk people with DM and metabolic diseases, and to patients. We are confident that these tools will be widely adopted in future, and that this movement will shape the realization of true "P4 medicine."

\section{CONFLICTS OF INTEREST}

Author Sang Youl Rhee is an advisor to The Vita Inc. and Finger Inc. Author Steven R. Steinhubl is an advisor to Livongo.

\section{ORCID}

Sang Youl Rhee https://orcid.org/0000-0003-0119-5818

Steven R. Steinhubl https://orcid.org/0000-0002-9256-7914

\section{ACKNOWLEDGMENTS}

This work was supported by the Bio Industrial Strategic Technology Development Program (20001234) funded By the Ministry of Trade, Industry \& Energy, Republic of Korea.

The authors would like to thank Professors Jeong-Taek Woo and Young Seol Kim of Kyung Hee University for their exceptional teaching and inspiration, which encouraged us to conduct the study.

\section{REFERENCES}

1. Cho NH, Shaw JE, Karuranga S, Huang Y, da Rocha Fernandes JD, Ohlrogge AW, Malanda B. IDF Diabetes Atlas: global estimates of diabetes prevalence for 2017 and projections for 2045. Diabetes Res Clin Pract 2018;138:271-81.

2. Won JC, Lee JH, Kim JH, Kang ES, Won KC, Kim DJ, Lee MK. Diabetes fact sheet in Korea, 2016: an appraisal of current status. Diabetes Metab J 2018;42:415-24.

3. Steinhubl SR, Topol EJ. Digital medicine, on its way to being just plain medicine. NPJ Digit Med 2018;1:20175.

4. Sharma A, Harrington RA, McClellan MB, Turakhia MP, Eapen ZJ, Steinhubl S, Mault JR, Majmudar MD, Roessig L, Chandross KJ, Green EM, Patel B, Hamer A, Olgin J, Rumsfeld JS, Roe MT, Peterson ED. Using digital health technology to better generate evidence and deliver evidence-based care. J Am Coll Cardiol 2018;71:2680-90.

5. Ricciardi W, Pita Barros P, Bourek A, Brouwer W, Kelsey T, Lehtonen L; Expert Panel on Effective Ways of Investing in Health (EXPH). How to govern the digital transformation of health services. Eur J Public Health 2019;29:7-12.

6. IQVIA: Digital health tools. Available from: https://www.iqvia. com/insights/the-iqvia-institute/reports/the-growing-valueof-digital-health (cited 2020 Oct 20).

7. Neborachko M, Pkhakadze A, Vlasenko I. Current trends of digital solutions for diabetes management. Diabetes Metab Syndr 2019;13:2997-3003.

8. Chin SO, Keum C, Woo J, Park J, Choi HJ, Woo JT, Rhee SY. Successful weight reduction and maintenance by using a smartphone application in those with overweight and obesity. Sci Rep 
2016;6:34563.

9. Tremmel M, Gerdtham UG, Nilsson PM, Saha S. Economic burden of obesity: a systematic literature review. Int J Environ Res Public Health 2017;14:435.

10. Arigo D, Jake-Schoffman DE, Wolin K, Beckjord E, Hekler EB, Pagoto SL. The history and future of digital health in the field of behavioral medicine. J Behav Med 2019;42:67-83.

11. McConnell MV, Shcherbina A, Pavlovic A, Homburger JR, Goldfeder RL, Waggot D, Cho MK, Rosenberger ME, Haskell WL, Myers J, Champagne MA, Mignot E, Landray M, Tarassenko L, Harrington RA, Yeung AC, Ashley EA. Feasibility of obtaining measures of lifestyle from a smartphone app: the myheart counts cardiovascular health study. JAMA Cardiol 2017;2:67-76.

12. Nelson BW, Allen NB. Accuracy of consumer wearable heart rate measurement during an ecologically valid 24-hour period: intraindividual validation study. JMIR Mhealth Uhealth 2019; 7:e10828.

13. Perez MV, Mahaffey KW, Hedlin H, Rumsfeld JS, Garcia A, Ferris T, Balasubramanian V, Russo AM, Rajmane A, Cheung L, Hung G, Lee J, Kowey P, Talati N, Nag D, Gummidipundi SE, Beatty A, Hills MT, Desai S, Granger CB, Desai M, Turakhia MP; Apple Heart Study Investigators. Large-scale assessment of a smartwatch to identify atrial fibrillation. N Engl J Med 2019;381:1909-17.

14. Liang Z, Chapa-Martell MA. Accuracy of fitbit wristbands in measuring sleep stage transitions and the effect of user-specific factors. JMIR Mhealth Uhealth 2019;7:e13384.

15. Davison BK, Quigg R, Skidmore PML. Pilot testing a photobased food diary in nine- to twelve-year old-children from Dunedin, New Zealand. Nutrients 2018;10:240.

16. Fuller NR, Fong M, Gerofi J, Ferkh F, Leung C, Leung L, Zhang $\mathrm{S}$, Skilton M, Caterson ID. Comparison of an electronic versus traditional food diary for assessing dietary intake: a validation study. Obes Res Clin Pract 2017;11:647-54.

17. Zeevi D, Korem T, Zmora N, Israeli D, Rothschild D, Weinberger A, Ben-Yacov O, Lador D, Avnit-Sagi T, Lotan-Pompan M, Suez J, Mahdi JA, Matot E, Malka G, Kosower N, Rein M, Zilberman-Schapira G, Dohnalova L, Pevsner-Fischer M, Bikovsky R, Halpern Z, Elinav E, Segal E. Personalized nutrition by prediction of glycemic responses. Cell 2015;163:107994.

18. Valdes AM, Walter J, Segal E, Spector TD. Role of the gut microbiota in nutrition and health. BMJ 2018;361:k2179.

19. Boerger NL, Barleen NA, Marzec ML, Moloney DP, Dobro J. The impact of specialized telephonic guides on employee en- gagement in corporate well-being programs. Popul Health Manag 2018;21:32-9.

20. Levinson CA, Fewell L, Brosof LC. My fitness pal calorie tracker usage in the eating disorders. Eat Behav 2017;27:14-6.

21. Shin DW, Yun JM, Shin JH, Kwon H, Min HY, Joh HK, Chung WJ, Park JH, Jung KT, Cho B. Enhancing physical activity and reducing obesity through smartcare and financial incentives: a pilot randomized trial. Obesity (Silver Spring) 2017;25:302-10.

22. Mahmood A, Kedia S, Wyant DK, Ahn S, Bhuyan SS. Use of mobile health applications for health-promoting behavior among individuals with chronic medical conditions. Digit Health 2019;5:2055207619882181.

23. Moin T, Damschroder LJ, AuYoung M, Maciejewski ML, Havens K, Ertl K, Vasti E, Weinreb JE, Steinle NI, Billington CJ, Hughes M, Makki F, Youles B, Holleman RG, Kim HM, Kinsinger LS, Richardson CR. Results from a trial of an online diabetes prevention program intervention. Am J Prev Med 2018; 55:583-91.

24. Jasik CB, Joy E, Brunisholz KD, Kirley K. Practical tips for implementing the diabetes prevention program in clinical practice. Curr Diab Rep 2018;18:70.

25. Mosst JT, DeFosset A, Sivashanmugam M, Kuo T. Exploring reimbursement options for the national diabetes prevention program: lessons learned from a pilot project in Los Angeles, 2014-2018. J Public Health Manag Pract 2020 Jan 30 [Epub]. https://doi.org/10.1097/PHH.0000000000001136.

26. Cha SA, Lim SY, Kim KR, Lee EY, Kang B, Choi YH, Yoon KH, Ahn YB, Lee JH, Ko SH. Community-based randomized controlled trial of diabetes prevention study for high-risk individuals of type 2 diabetes: lifestyle intervention using web-based system. BMC Public Health 2017;17:387.

27. Norris SL, Engelgau MM, Narayan KM. Effectiveness of selfmanagement training in type 2 diabetes: a systematic review of randomized controlled trials. Diabetes Care 2001;24:561-87.

28. Greenwood DA, Gee PM, Fatkin KJ, Peeples M. A systematic review of reviews evaluating technology-enabled diabetes selfmanagement education and support. J Diabetes Sci Technol 2017;11:1015-27.

29. Mierzwa S, Souidi S, Conroy T, Abusyed M, Watarai H, Allen T. On the potential, feasibility, and effectiveness of chat bots in public health research going forward. Online J Public Health Inform 2019;11:e4.

30. Rhee SY, Han SW, Woo JT. Artificial pancreas: a concise review. J Korean Diabetes 2017;18:141-9.

31. Voelker R. “Artificial pancreas” is approved. JAMA 2016;316:1957. 
32. DeVries JH. The artificial pancreas-ready for prime time? Lancet Diabetes Endocrinol 2017;5:238-9.

33. Kim J, Sempionatto JR, Imani S, Hartel MC, Barfidokht A, Tang G, Campbell AS, Mercier PP, Wang J. Simultaneous monitoring of sweat and interstitial fluid using a single wearable biosensor platform. Adv Sci (Weinh) 2018;5:1800880.

34. Park J, Kim J, Kim SY, Cheong WH, Jang J, Park YG, Na K, Kim YT, Heo JH, Lee CY, Lee JH, Bien F, Park JU. Soft, smart contact lenses with integrations of wireless circuits, glucose sensors, and displays. Sci Adv 2018;4:eaap9841.

35. Huang Z, Tan E, Lum E, Sloot P, Boehm BO, Car J. A smartphone app to improve medication adherence in patients with type 2 diabetes in Asia: feasibility randomized controlled trial. JMIR Mhealth Uhealth 2019;7:e14914.

36. Peters-Strickland T, Pestreich L, Hatch A, Rohatagi S, Baker RA, Docherty JP, Markovtsova L, Raja P, Weiden PJ, Walling DP. Usability of a novel digital medicine system in adults with schizophrenia treated with sensor-embedded tablets of aripiprazole. Neuropsychiatr Dis Treat 2016;12:2587-94.

37. Eiland L, McLarney M, Thangavelu T, Drincic A. App-based insulin calculators: current and future state. Curr Diab Rep 2018; 18:123.

38. Klonoff DC, Kerr D. Smart pens will improve insulin therapy. J Diabetes Sci Technol 2018;12:551-3.

39. Shanmugam MP, Mishra DK, Madhukumar R, Ramanjulu R, Reddy SY, Rodrigues G. Fundus imaging with a mobile phone: a review of techniques. Indian J Ophthalmol 2014;62:960-2.

40. Rajalakshmi R, Arulmalar S, Usha M, Prathiba V, Kareemuddin KS, Anjana RM, Mohan V. Validation of smartphone based retinal photography for diabetic retinopathy screening. PLoS One 2015;10:e0138285.

41. Basatneh R, Najafi B, Armstrong DG. Health sensors, smart home devices, and the internet of medical things: an opportunity for dramatic improvement in care for the lower extremity complications of diabetes. J Diabetes Sci Technol 2018;12:57786.

42. Habib MA, Mohktar MS, Kamaruzzaman SB, Lim KS, Pin TM, Ibrahim F. Smartphone-based solutions for fall detection and prevention: challenges and open issues. Sensors (Basel) 2014; 14:7181-208.

43. Rushakoff RJ, Sullivan MM, MacMaster HW, Shah AD, Rajkomar A, Glidden DV, Kohn MA. Association between a virtual glucose management service and glycemic control in hospitalized adult patients: an observational study. Ann Intern Med 2017;166:621-7.
44. Shan R, Sarkar S, Martin SS. Digital health technology and mobile devices for the management of diabetes mellitus: state of the art. Diabetologia 2019;62:877-87.

45. Kumar RB, Goren ND, Stark DE, Wall DP, Longhurst CA. Automated integration of continuous glucose monitor data in the electronic health record using consumer technology. J Am Med Inform Assoc 2016;23:532-7.

46. Castro Sweet CM, Chiguluri V, Gumpina R, Abbott P, Madero EN, Payne M, Happe L, Matanich R, Renda A, Prewitt T. Outcomes of a digital health program with human coaching for diabetes risk reduction in a medicare population. J Aging Health 2018;30:692-710.

47. Michaelides A, Raby C, Wood M, Farr K, Toro-Ramos T. Weight loss efficacy of a novel mobile diabetes prevention program delivery platform with human coaching. BMJ Open Diabetes Res Care 2016;4:e000264.

48. Jardine J, Fisher J, Carrick B. Apple’s ResearchKit: smart data collection for the smartphone era? J R Soc Med 2015;108:294-6.

49. Bot BM, Suver C, Neto EC, Kellen M, Klein A, Bare C, Doerr M, Pratap A, Wilbanks J, Dorsey ER, Friend SH, Trister AD. The mPower study, Parkinson disease mobile data collected using ResearchKit. Sci Data 2016;3:160011.

50. Egger HL, Dawson G, Hashemi J, Carpenter KLH, Espinosa S, Campbell K, Brotkin S, Schaich-Borg J, Qiu Q, Tepper M, Baker JP, Bloomfield RA Jr, Sapiro G. Automatic emotion and attention analysis of young children at home: a ResearchKit autism feasibility study. NPJ Digit Med 2018;1:20.

51. Yamaguchi S, Waki K, Nannya Y, Nangaku M, Kadowaki T, Ohe K. Usage patterns of gluconote, a self-management smartphone app, based on ResearchKit for patients with type 2 diabetes and prediabetes. JMIR Mhealth Uhealth 2019;7:e13204.

52. Baca-Motes K, Edwards AM, Waalen J, Edmonds S, Mehta RR, Ariniello L, Ebner GS, Talantov D, Fastenau JM, Carter CT, Sarich TC, Felicione E, Topol EJ, Steinhubl SR. Digital recruitment and enrollment in a remote nationwide trial of screening for undiagnosed atrial fibrillation: lessons from the randomized, controlled mSToPS trial. Contemp Clin Trials Commun 2019;14:100318.

53. Steinhubl SR, Waalen J, Edwards AM, Ariniello LM, Mehta RR, Ebner GS, Carter C, Baca-Motes K, Felicione E, Sarich T, Topol EJ. Effect of a home-based wearable continuous ECG monitoring patch on detection of undiagnosed atrial fibrillation: the mSToPS randomized clinical trial. JAMA 2018;320:146-55.

54. Izmailova ES, Wagner JA, Perakslis ED. Wearable devices in clinical trials: hype and hypothesis. Clin Pharmacol Ther 2018; 
104:42-52.

55. Lee TT, Kesselheim AS. U.S. Food and drug administration precertification pilot program for digital health software: weighing the benefits and risks. Ann Intern Med 2018;168:730-2.

56. U.S. Food and Drug Administration: Digital Health Software Precertification (Pre-Cert) Program 2020. Available from: https://www.fda.gov/medical-devices/digital-health-centerexcellence/digital-health-software-precertification-pre-certprogram (updated 2020 Sep 14).

57. Frieden TR. Evidence for health decision making: beyond randomized, controlled trials. N Engl J Med 2017;377:465-75.

58. Kim JA, Yoon S, Kim LY, Kim DS. Towards actualizing the value potential of Korea Health Insurance Review and Assessment (HIRA) data as a resource for health research: strengths, limita- tions, applications, and strategies for optimal use of HIRA data. J Korean Med Sci 2017;32:718-28.

59. Park SY, Jeong SJ, Ustulin M, Chon S, Woo JT, Lim JE, Oh B, Rhee SY. Incidence of diabetes mellitus in male moderate alcohol drinkers: a community-based prospective cohort study. Arch Med Res 2019;50:315-23.

60. Keesara S, Jonas A, Schulman K. Covid-19 and health care's digital revolution. N Engl J Med 2020;382:e82.

61. Bradley WG, Golding SG, Herold CJ, Hricak H, Krestin GP, Lewin JS, Miller JC, Ringertz HG, Thrall JH. Globalization of P4 medicine: predictive, personalized, preemptive, and participatory: summary of the proceedings of the Eighth International Symposium of the International Society for Strategic Studies in Radiology, August 27-29, 2009. Radiology 2011;258:571-82. 